\title{
ANALYSIS OF THE METAL LOAD STRUCTURE WHEN DESIGNING STEELS IN ELECTRIC ARC FURNACES
}

\author{
Ana SOCALICI ${ }^{1, *}$, Cristina PACURAR ${ }^{2}$, Corneliu BIRTOK BANEASA ${ }^{1}$, \\ Adina BUDIUL BERGHIAN ${ }^{1}$, Oana GAIANU ${ }^{1}$ \\ ${ }^{1}$ University Politehnica of Timișoara, Faculty Engineering of Hunedoara, \\ Department of Engineering and Management, Revolutiei Str., no.5, 331128, Hunedoara, Romania. \\ ${ }^{2}$ Technological High School Transilvania Deva, 22 December Str., no.116, 330167, Deva, Romania.
}

\begin{abstract}
In the steel industry, scrap metal is an important raw material resource for the electric arc furnace. The overall steel recycling rate is estimated at around $85 \%$. The work presents an analysis of the structure of the metal load when elaborating steels in electric arc furnaces. The metal load consists of different categories of scrap metal. The influence of the quality of these types of waste on the recycling process and on the finished product by investigating the effect of the composition of the load on the steel removal is presented.
\end{abstract}

Keywords: raw materials, scrap metal, steel, steel removal

\section{Introduction}

The achievement of the objectives proposed by the steel plants depends on the researchdevelopment-innovation potential in ensuring the superior quality for the materials and raw materials intended for the loading of metallurgical furnaces $[1,2]$. The essential aspect related to the importance of the purity of the raw materials that make up the primary load of the streams lies in their potential not to transmit to the elaborated steel waste metals that negatively influence some technological properties. Scrap metal, at present, has become a real cause of contamination of the final steel with unwanted residual metals [3]. Scrap metal tends to become a deficient material both economically and technologically. For such reasons, concerns are intensifying for the manufacture of new materials or by-products intended as substitutes for scrap metal $[4,5]$. The duration of melting is determined by the degree of preparation of the load, its compaction, the power of the transformer and the management of the melt. During melting, in parallel with the physical process of the passage of the charge in the liquid state, physico-chemical processes of oxidation of the elements and slag formation take place. When elaborating steel in electric furnaces with arc-type EBT in principle, two categories of problems are distinguished: some regarding the way of composition and preparation of the load, and others regarding the thermal regime [6]. These two main problems condition each other, adapt according to the chemical composition and the quality of the steel and are subordinated to the need to make high-quality steels, characterized by a high degree of purity of gases and non-metallic inclusions, low content of harmful elements and a determined value of the hereditary size of austenite grain $[7,8]$. It should also be borne in mind that elaboration in economic conditions requires the achievement of high quality on large production batches, under the conditions of achieving at the same time 
some high specific productivity and productions, specific low consumptions (primarily of electricity, fuels and electrodes) and the removal of liquid steel as high as possible.

When preparing and making the load, account must be taken of the intended purpose and at the same time, depending on the economic situation, the momentary availability in raw materials and additive materials $[9,10]$. The preparation of the load mainly aims at better use of the elaboration aggregate in order to reduce the melting duration, the thermal losses and increase the durability of the refractory lining.

\section{Methodology of Production}

In order to ensure proper conditions for obtaining a superior quality, it is recommended that when drawing steels to use metal loads of good quality, not rusted and with low content of phosphorus and sulphur (desirable below $0.04 \%$ ), as far as possible without non-ferrous metals $(\mathrm{Cu}, \mathrm{Sn}, \mathrm{Zn}, \mathrm{Pb}$, etc.), concrete, refractory debris, earth, etc. The metal load must be prepared in such a way as to ensure the lowest possible loading time [11, 12]. The proportions of materials in the entire composition of the load shall be determined based on the oxygen and carbon balance equations, taking into account also the available types of scrap metal.

The work presents an analysis of the structure of the metal load when drawing steel in electric arc furnaces. The analysis was carried out on 70 steelyards elaborated at the electric steel mill equipped with an electric arc furnace type EBT, with a processing plant in the LF pot, a VD vacuuming plant and a continuous casting plant, the cast semi-finished products being blooms, tiles and round profiles [12].

In the analysis, a number of parameters were followed:

- metal load components: scrap metal classes E1, E3, E5, E100, ferrous barks and scrap metal from internal recycling;

- auxiliary materials for the formation of slag: lime, dolomite lime, dolomite, bauxite, foaming material, coke, TopexCa, Topex;

- additions for the refining process: lime, graphite, carbon blown through the injectors, oxygen blown through the injectors, oxygen lance, methane gas blown through the injectors; aluminium;

- additions for the deoxidation process: ferromanganese, ferrosilicon, silicomanganese,

- the duration of the technological stages of elaboration;

- electricity consumption;

- the content of residual elements.

It was analyzed the structure of the load, the state of its presentation in terms of dimensional, of the slag content both for the barks coming from the internal, mostly from the slag dumps, but also from the trade [12]. It was also analyzed the quality of the prepared scrap metal E1, E3, E5, E100, of the scrap iron coming from internal recycling, in terms of rust content, nonferrous metals, earth and sand.

Regarding the composition of the metal load, the high share in the total metallic load is held by the scrap metal quality E1 and E3, their average being $37 \%$ and $31 \%$, respectively. Regarding the consumption of internal bark, it reached up to $21 \mathrm{t} /$ charge, with the average value being $9 t$; in several cases the barks had a high slag content, being cases in which for this reason this assortment was rejected and the consumption of barks from the trade (outside the steel company) varied between $1.5 \mathrm{t}$ to $25 \mathrm{t} / \mathrm{charge}$, the average value being of $15 \mathrm{t} / \mathrm{batch}$. The scrap metal from internal recycling varied within large limits of 9-22t/batch, the average value being $12 \mathrm{t} / \mathrm{batch}$, this assortment of scrap metal is of good quality, advanced prepared, coming from the entire technological flow so that the chemical composition is known within limited limits. The scrap metal from scrapping did not exceed $12 \mathrm{t} / \mathrm{batch}$, which is correct, because its origin is not known precisely, which can bring into steel unwanted elements considered residual elements, so 
limited in content. Particular attention should be paid to the E5 and E100 components, as this assortment can bring non-ferrous metals (span mixed with non-ferrous alloys).

From an assortment point of view, the materials introduced into the load (in the bucket) varied within quite large limits. The additions during the elaboration of the charge, although they varied within large limits, can be considered they were well correlated with the composition of the metal bath. The analysis of the duration of the main technological stages clearly highlights the possibility of reducing the duration of the technological operations by increasing the degree of scrap metal processing. In the analysed batches there are very large variations for the weight of the metal load, of the liquid steel and the liquid steel removal, the main cause being the quality of the metal load, respectively the proportion of non-metallic component in the metallic assortment of the load. As for the weight of the metal load, it ranged from 132 to 98 tons.

Regarding the weight of liquid steel, the average value was 105 tons. The removal of liquid steel, varied within very high limits, more precisely between $99 \%$ and $75 \%$. The values for the removal of liquid steel relative to the current values obtained in industrial practice can be considered quite low. There should be no batches to which normally the removal is below $80 \%$. The low values of liquid steel removal are caused by the poor quality of the metal load especially of the barks, an assortment at which the actual iron content is well below the estimated one. The variation in the removal of liquid steel from one batch to another is the result of the fact that the structure of the metal load is not constant, and also neither is its quality. In such cases, it would be normal to follow the quality of the metal load on the metal load-receiving flow - metal load preparation - load dump and furnace

Regarding the residual elements $\mathrm{Cr}, \mathrm{Ni}$, Mo there were no cases of exceeding the imposed limits. Electricity consumption varies between $552-582 \mathrm{kWh} / \mathrm{t}$ liquid steel, this can be considered an acceptable variation gave the quality of the load. Advanced load preparation leads to a reduction in specific energy consumption.

\section{Material and Methodology of Research}

The experimental data were processed in the Excel calculation program, it was taken into account the establishment of simple correlations between the removal of liquid steel and the proportion of the assortments of the metal load used to compose the batch. The obtained results are presented in figs. 1-6 both in graphical and analytical form, the correlations being significant considering a large number of analysed yards. In order to establish double correlations, in the Matlab program, the data were processed using the correlation equation:

$$
z=a_{1} x^{2}+a_{2} y^{2}+a_{3} x y+a_{4} x+a_{5} y+a_{6}
$$

where:

$\mathrm{z}$ - removal of liquid steel, [\%] - dependent parameter;

$\mathrm{x}, \mathrm{y}$ - proportion of metal components in charge, [\%] - independent parameters.

Fig.7-10 shows the level curves and the regression surfaces obtained. From the data presented in the graphic representations, there is a variation within large limits of the liquid metal removal, which can be explained by the degree of readiness of each assortment of scrap metal. The increase in the load of the proportions of the assortments of scrap iron E1, E3 and E5 lead to the increase of the removal, explained by their quality and by the advanced degree of readiness. 


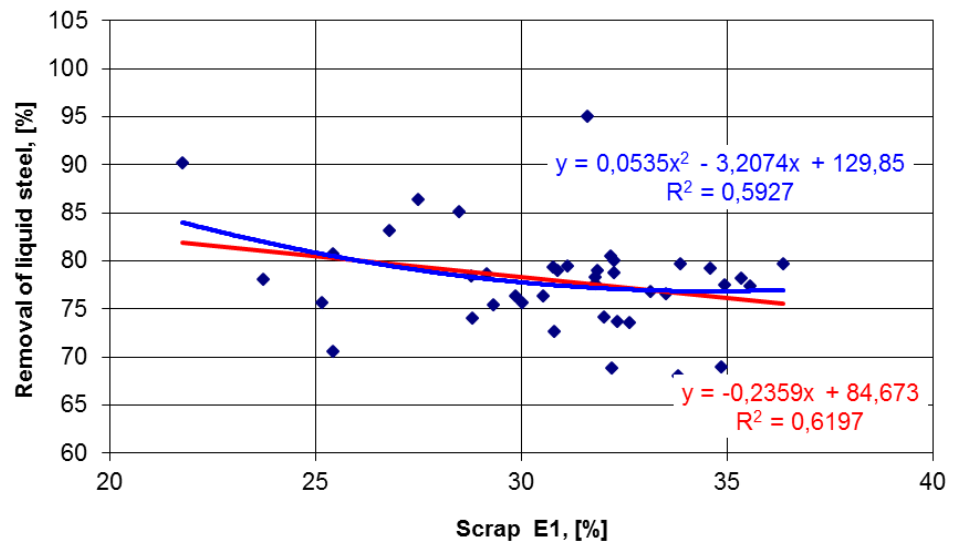

Fig. 1. Correlation $=f($ Scrap metal E1 $)$

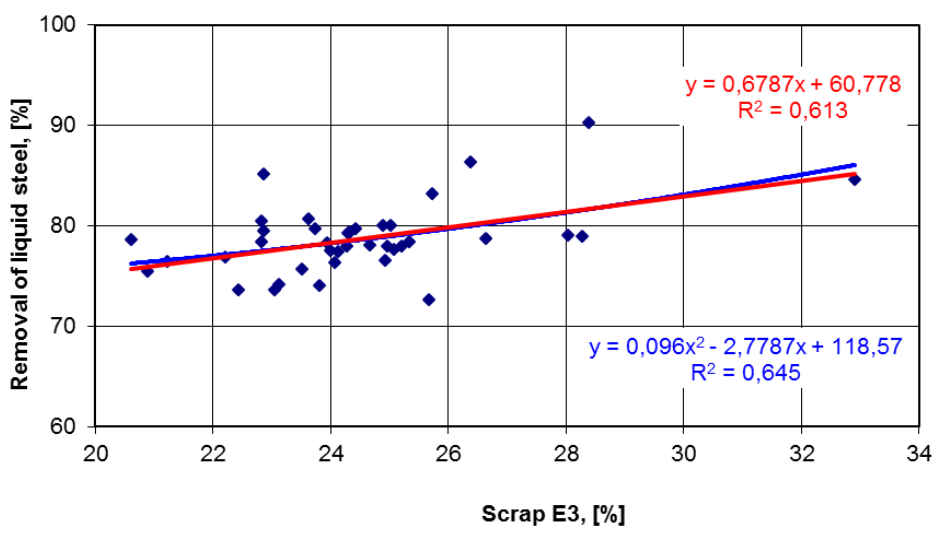

Fig. 2. Correlation $=f($ Scrap metal E3)

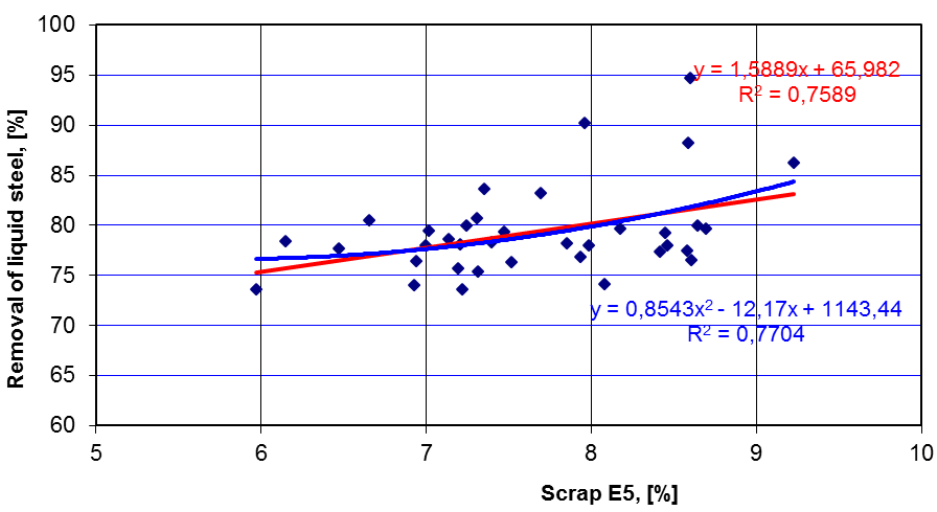

Fig. 3. Correlation $=f($ Scrap metal E5) 


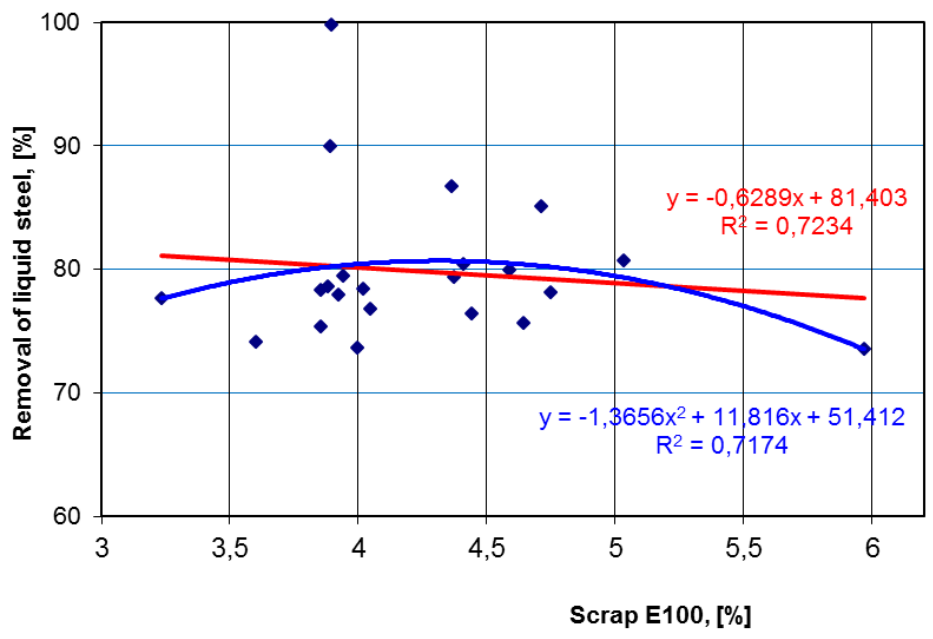

Fig. 4. Correlation $=\mathrm{f}($ Scrap metal E100 $)$

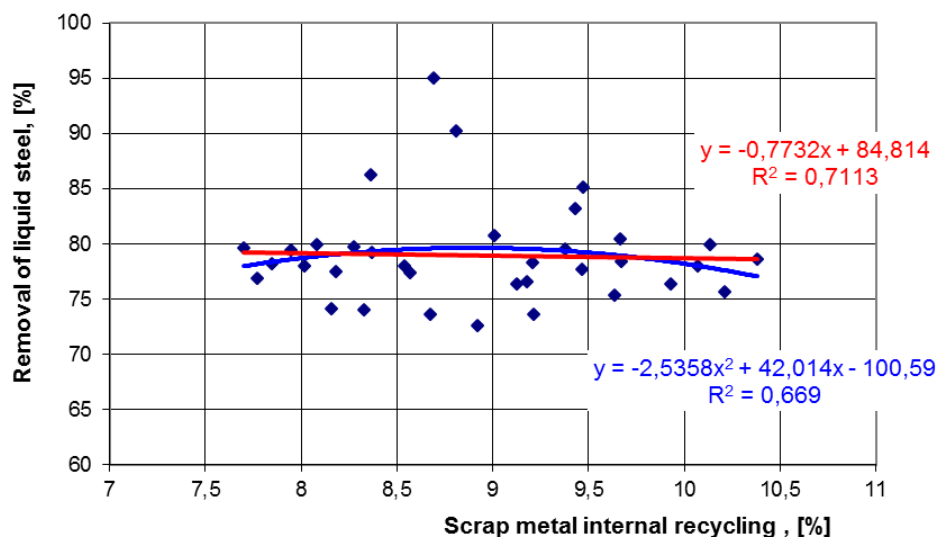

Fig. 5. Correlation $=\mathrm{f}($ Scrap metal internal recycling $)$

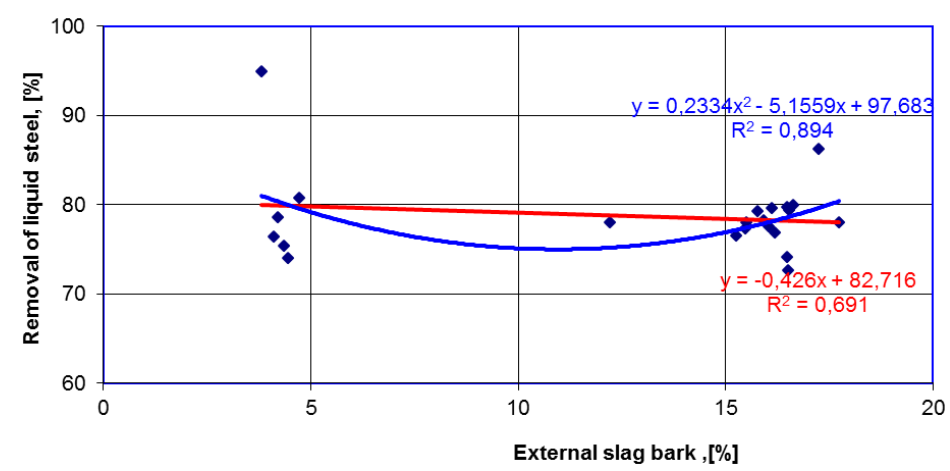

Fig. 6. Correlation = f (External slag bark $)$ 


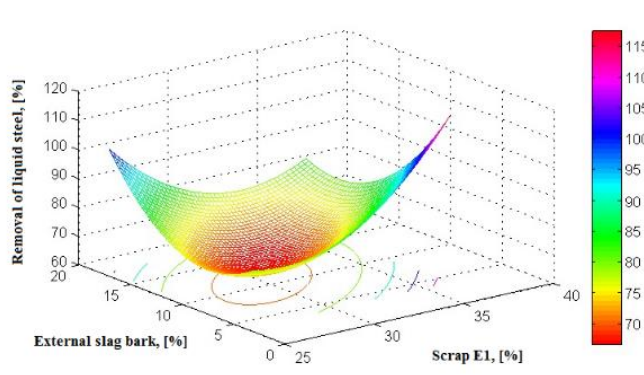

a)

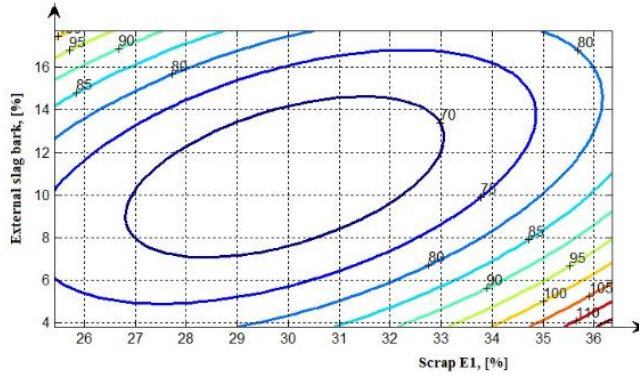

b)

Fig. 7. Correlation $=f($ External slag bark,Scrap metal E1 $): a_{1}=0.4546972 ; a_{2}=0.3103931 ; a_{3}=-0.37071805 ; a_{4}=-$ 23.19604277; $\mathrm{a}_{5}=4.3594152 ; \mathrm{a}_{6}=390.1234967 ; \mathrm{D}=0.42710779 ; \mathrm{H}=0.9093944 ; \mathrm{R}^{2}=0.6940553$ : a) regression surface; b) level curves

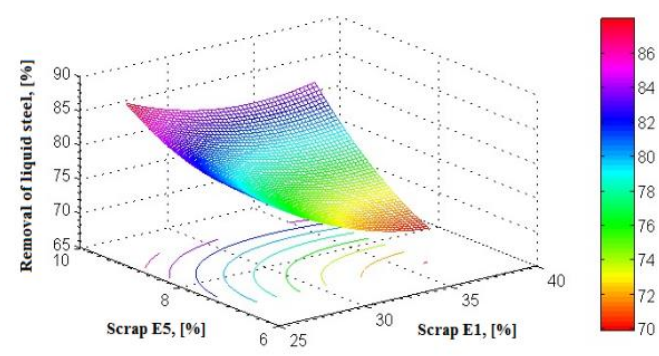

a)

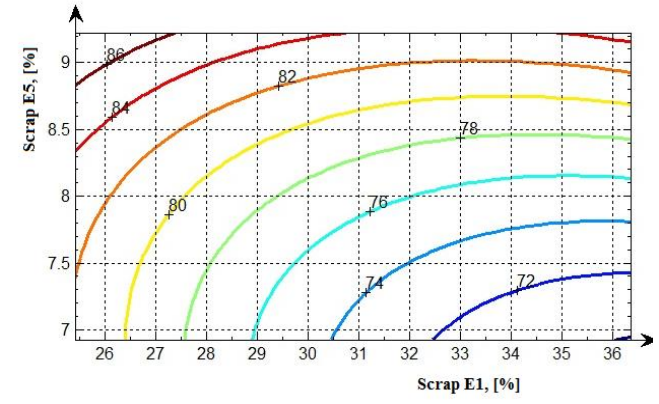

b)

Fig. 8. Correlation $=f($ Scrap metal E5, Scrap metal E1 $) a_{1}=0.0788109 ; a_{2}=1.269789 ; a_{3}=0.34081517 ; a_{4}=-8.3174359$; $\mathrm{a}_{5}=-26.4914911 ; \mathrm{a}_{6}=304.8916763 ; \mathrm{D}=0.28413797 ; \mathrm{H}=0.1576218 ; \mathrm{R}^{2}=0.5272306$ : a) regresion surface; $\left.\mathrm{b}\right)$ level curves

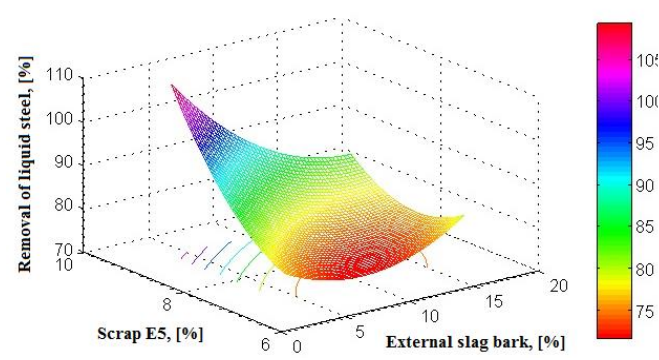

a)

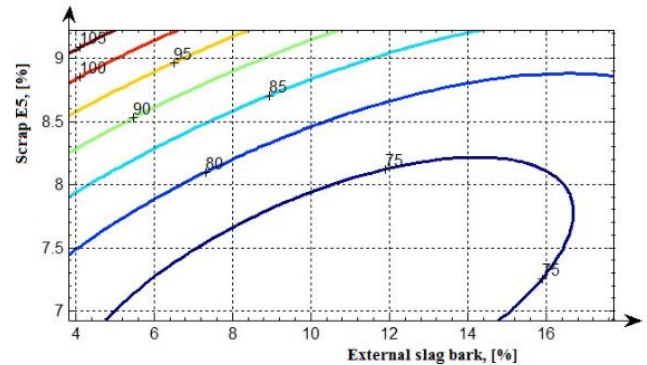

b)

Fig. 9. Correlation $=f($ Scrap E5, External slag bark $): a_{1}=0.1331906 ; a_{2}=4.1352397 ; a_{3}=-0.92176192 ; a_{4}=3.7782414$; $a_{5}=-48.9459035 ; a_{6}=225.028473 ; \mathrm{D}=1.3534558 ; \mathrm{H}=0.26638127 ; \mathrm{r}^{2}=0.803576$ : a) regression surface; $b$ ) level curves 


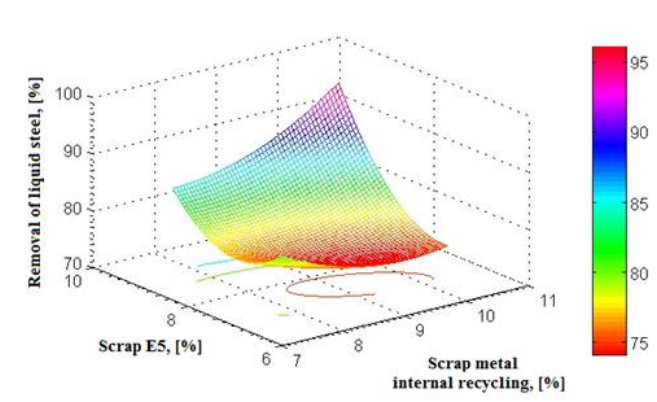

a)

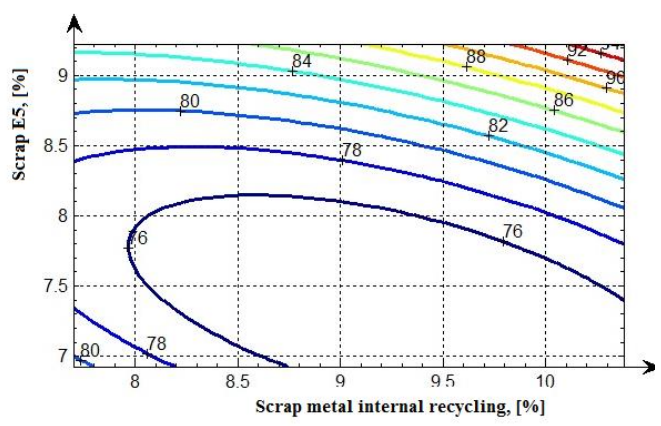

b)

Fig. 10. Correlation $=f\left(\right.$ Scrap metal internal recycling, Scrap metal E5), $a_{1}=1.5043352 ; a_{2}=4.235312 ; a_{3}=2.7013661$; $\mathrm{a}_{4}=-47.837609 ; \mathrm{a}_{5}=-87.4215727 ; \mathrm{a}_{6}=617.979357 ; \mathrm{D}=18.1879368 ; \mathrm{H}=3.0086704 ; \mathrm{r}^{2}=0.43754224 ;$ a) regressions surface; b) level curves

The use of commercial rind in a proportion of $18-20 \%$ leads to a removal of $85-92 \%$, this assortment being well controlled and advanced prepared because severe conditions are imposed at the reception. Also, for cargo proportions of 8-10\% scrap metal from internal recycling and 3.5 $-5 \%$ E100 assortment, high values are obtained for removal, these assortments can be relatively easily controlled. A more particular problem arises with the use of internal barks, especially those that come from the slag heap, since they are not sufficiently processed, which leads to variable contents of the non-metallic part, and thus to a decrease in the pulling out.

It is obvious that from the analysis of the correlation diagrams, represented graphically, in particular, the plane projection of the level curves, a component of the load can be established, leading to obtaining higher values for the extraction of liquid steel (under the conditions given for the availability of the existing metal assortments in the warehouse, respectively of the supply conditions).

\section{Conclusions}

Summarizing the results of the research carried out, the following can be concluded:

- the electric arc furnace type EBT is the most appropriate aggregate for processing the scrap metal in order to obtain steel, both in terms of the quality of the load and the number of assortments introduced into the load;

- the structure of the load may vary within large limits in terms of assortment, provided that it is advanced prepared;

- the variation within large limits of the weight of the metal load was determined as a result of the variation of the share of different types of scrap metal;

- the assortment structure of the scrap metal does not lead to exceeding the content of residual elements, leading to the downgrading of the yards;

- the quality of the scrap metal, especially of the barks coming from both inside and outside, is reflected in the level of removal;

- in current practice, the quality of the load is also determined by economic considerations, these being made according to the elaborated steel brand, differing obviously from one steel mill to another.

Based on the analysis and depending on the possibilities of supplying different types of metal load (available from the warehouse) for the current conditions (both technological and economic and environmental considerations are taken into account) it is recommended to use the following assortments in the metallic load: 30-40\%E1, 20-25\%E3, 5-10\%E5, 4-6\% E100, 10$20 \%$ ferrous barks, $8-10 \%$ scrap metal from domestic recycling. 
The quality of the scrap metal is a limiting factor for the increased use of its various sorts. Certain types of waste contain large amounts of elements harmful to the quality of steel. Industrial practice is gradually moving towards the production of high-quality products and the decrease in the quality of steel waste and the increase in steel quality can pose serious challenges for recycling. The lower the quality of the waste, the lower the yield, and therefore the energy requirement per tonne of production desired is higher.

\section{References}

[1] M. Haupt, C.Vadenbo, C. Zeltner, S. Hellweg, Influence of Input-Scrap Quality on the Environmental Impact of Secondary Steel Production, Journal of Industrial Ecology, 21(2), 2017, pp. 391-401.

[2] R. Boom, R. Steffen, Recycling of scrap for high quality steel products, Steel Research, 72(3), 2001, pp. 91-96.

[3] B. Bettayeb, S.J. Bassetto, M. Sahnoun, Quality control planning to prevent excessive scrap production, Journal of Manufacturing Systems, 2014, 33, pp. 400-411.

[4] M. Ruth, Steel Production and Energy, Encyclopedia of Energy, 2004.

[5] N. Avram N, Sustainable development in the steel industry by capitalizing on secondary materials, Printech, Bucharest, Romania, 2014.

[6] F. Drăgoi, Research on reducing the gas content of steels developed and treated on the technological flow EBT - LF, PhD Thesis, Politehnica, Timisoara, Romania, 2012.

[7] A. Puțan, Research on the refining of steel made on the flow of electric arc furnace - furnace pot - continuous casting, PhD Thesis, Politehnica, Timisoara, Romania, 2013.

[8] U.B. Pal, S.A. MacDonald, D.W. Woolley, A.C. Powell, Results demonstrating techniques for enhancing electrochemical reactions involving iron oxide in slags and $C$ in liquid iron. Metall. Mater. Trans. B, 2005, 36, pp. 209-218.

[9] N. Hui-Teng, H. Cheng-Yong, M. Abdullah, N. Yong-Sing, R. Bayuaj, Study of fly ash geopolymer and fly ash/slag geopolymer in term of physical and mechanical properties, EUR J MATER SCI ENG 2020, 5, 4, pp.187-198.

[10] W.D. Judge, J. Paeng, G. Azimi, Electrorefining for direct decarburization of molten iron, Nature Materials, 54(3), 2021, pp. 491-494.

[11] https://corporate.arcelormittal.com/sustainability/by-products-scrap-and-the-circulareconomy, accessed December 02, 2021.

[12] C. Pacurar, Research on the influence of the structure of the metal load on the reduction of specific consumption and the degree of pollution in electric steelworks, PhD Thesis,

Politehnica, Timisoara, Romania, 2019.

Received: November 08, 2021

Accepted: December 17, 2021 